\section{Gentle but effective interdental cleaning}

To discover the benefits of the Wisdom Clean Between Rubber Interdental Brushes, don't miss your opportunity to do so at the BDIA Dental Showcase 2018 this year.

Clinically proven to reduce gingival disease, these are the No. 1 selling rubber interdental brushes in the UK. The wire and latex-free solutions feature flexible, tapered brush heads and micro-fine rubber filaments that glide smoothly between the teeth for a gentle yet effective clean.

Available in three sizes, the Wisdom Clean Between Interdental Brushes are ideal for anyone who has previously found wire interdental brushes difficult or uncomfortable to use.

Also on display at

Showcase will be the Wisdom

Clean Between Easy Slide

Tensioning Flossers, with

a new Waveform Tension

Control System that ensures

the tape remains taut so as

to slide effortlessly between

the teeth. The silk-like tape

is shred resistant and gentle on the soft tissue, thereby maximising patient comfort.

To find out more about these and other products,

visit Wisdom Toothbrushes on stand N40 at the BDIA Showcase, visit www.wisdomtoothbrushes.com or call 01440714800 .

\section{Come take a seat}

Belmont invites delegates at the BDIA Dental Showcase 2018 to take a seat in one of its stunning treatment centres at Stand J35.

Its flagship Cleo II features a unique folding leg rest, which has a much smaller footprint than a conventional chair and is also far more familiar in design to patients, and thereby less intimidating for them.

For those requiring the flexibility of an ambidextrous unit, there's either the tbCompass or the Voyager III. With Belmont treatment centres, there is also a huge array of colours from which to choose, so customers can co-ordinate perfectly with the rest of their interior.

With a patient perfectly positioned, you need an operating light that will provide a flooded area of illumination, with minimum heat transfer and white light, which most closely matches daylight.

The 900 LED light from Belmont does just that. Also, launching at Showcase will be an innovation designed to be as practical as it is impressive.

\section{Spoilt for choice}

Delegates at this year's BDIA Dental Showcase 2018 will be spoilt for choice on exclusive offers and innovative product launches.

Industry-leading manufacturer W\&H is excited to be exhibiting the latest clinical solutions including the advanced Osstell Beacon handheld device, which identifies when an implant is ready for loading, thereby improving osseointegration.

Delegates can explore how the intuitive Implantmed can enable them to assume utmost control of surgical implant procedures, thanks to the unit's automatic thread cutter function and customisable W\&H Osstell ISQ module.

The expert team from W\&H can demonstrate how the Assistina TWIN handpiece care and maintenance unit provides a costeffective solution
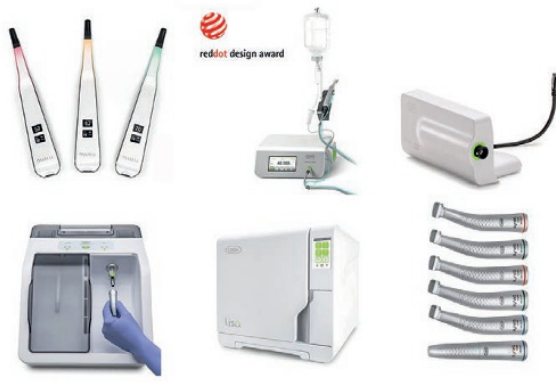
to extending the working life of handpieces.

Delegates can also find out how sterilization procedures can be streamlined with the user-friendly Lisa type B vacuum sterilizer, featuring Eco Dry technology that adapts the drying time to the mass of each load.

These innovative products make up a catalogue of high quality dental technology that also includes the Piezomed unit and the award-winning Synea Vision range of powerful handpieces.

Meet W\&H at Stand I22 at the BDIA Dental Showcase to discover the latest products on offer, including the new Piezomed Implant Tips and the Proxeo Twist Prophy handpiece for improved access to the oral cavity.

More information is available at www.wh.com/en_uk or by calling 01727874990 or emailing office.uk@wh.com.

\section{Wholesaler with a difference}

Dental Sky's customers are people, not account numbers. The company says it likes to keep things simple and doesn't believe in confusing promotions and will never knowingly be undersold.

It offers a broad range of sundries and is the sole distributor for The Wand, a computer Assisted Anesthesia System, capable of providing virtually pain-free dentistry. It also exclusively distributes Orabloc 4\% Articaine.

Manufactured by Pierrel it is the only aseptically manufactured local anaesthetic available in the UK. Orabloc has an impressive shelf life - 24 months at room temperature. Efficiency is ensured, with rapid onset of anaesthesia from one to three minutes and the $\mathrm{pH}$ of the solution (which makes the injection less painful for the patient) remains stable through the lifetime of the product.

More information is available by visiting Dental Sky at the BDIA Dental Showcase 2018 at Stand N45 or by visiting https:// www.dentalsky.com/. 